\title{
Prioritas Pengembangan Infrastruktur Pada Kawasan Ekonomi Khusus Bidang Pariwisata Tanjung Lesung Di Kabupaten Pandeglang
}

\author{
Benyamin Yacob dan Eko Budi Santoso \\ Departemen Perencanaan Wilayah dan Kota, Fakultas Arsitektur Desain dan Perencanaan \\ Institut Teknologi Sepuluh Nopember \\ e-mail: eko_budi@urplan.its.ac.id
}

\begin{abstract}
Abstrak-Kawasan Ekonomi Khusus merupakan kawasan yang ditentukan untuk menjadi lokomotiv perekonomian bagi kawasan disekitarnya. Tanjung Lesung sebagai kawasan Pariwisata yang berada di Kabupaten Pandeglang menjadi salah satu Kawasan Ekonomi Khusus Pariwisata dengan ditetapkannya berdasarkan Peraturan Pemerintah nomor 26 tahun 2012. Tanjung lesung yang berada pada desa Tanjung Jaya Kecamatan Panimbang memiliki beberapa kendala seperti kurangnya akses menuju KEK Tanjung Lesung, Fasilitas pendukung dan sarana prasarana pendukung yang kurang memadai sehingga menghambat pembangunan yang ada. Penelitian ini bertujuan untuk mencari prioritas pengembangan infrasrtuktur yang diperlukan pada Kawasan Ekonomi Khusus Tanjung Lesung dengan memiliki 2 sasaran penelitian. Tahap awal penelitian ini adalah mengidentifikasi kebutuhan infrastruktur penunjang pembangunan KEK Tanjung Lesung yang diperlukan dengan menggunakan anlisis Delphi. Kedua, Menentukan Prioritas infrastruktur yang dibutuhkan dengan menggunakan alat analisis Analytical Hierarchy Process (AHP). Hasil dari penelitian ini menunjukan bahwa terdapat 15 infrastruktur yang diperlukan KEK Tanjung Lesung, dengan urutan prioritas sebagai berikut (1)Kondisi jalan (2) Jaringan listrik (3) Fasilitas Penginapan dan Hotel (4) Fasilitas pelayanan keamanan (5) Moda Transportasi (6) Fasilitas Pendukung Transportasi (7) Fasilitas pelayanan perbelanjaan (8) Moda transportasi (9) Fasilitas pendukung transportasi (10) Fasilitas pelayanan perbelanjaan (11) Telekomunikasi (12) Sistem pengelolaan limbah dan sanitasi (13) Fasilitas pelayanan keuangan (14) Drainase (15) Persampahan.
\end{abstract}

Kata Kunci-Infrastruktur, kawasan pariwisata, pengembangan kawasan, prioritas infrastruktur

\section{PENDAHULUAN}

$\mathrm{T}$ ANJUNG Lesung sesuai dengan Peraturan Pemerintah Nomor 26 tahun 2012 telah ditetapkan menjadi Kawasan Ekonomi Khusus bidang Pariwisata. KEK sendiri menurut Undang - Undang nomor 39 tahun 2009 adalah kawasan dengan batas tertentu dalam wilayah hukum NKRI yang ditetapkan untuk menyelenggarakan fungsi perekonomian dan memperoleh fasilitas tertentu. KEK memiliki bentuk berupa kawasan yang terdiri dari satu atau beberapa zona seperti pengolahan ekspor, logisik, industri, pengembangan teknologi, pariwisata, energi atau ekonomi lain. Adapun kriteria yang telah dicapai Tanjung Lesung sehingga menjadi Kawasan Ekonomi Khusus adalah (1) sudah sesuai denga RTRW dan tidak berpotensi mengganggu kawasan lindung (2) pemerintah daerah mendukung KEK (3) Terletak pada wilayah pontensi sumber daya unggulan (4) mempunyai batas yang jelas [1].

Wilayah Administrasi KEK Tanjung Lesung berada pada desa Tanjung Jaya Kecamatan Panimbang Kabupaten Pandeglang. Batas administrasi KEK Tanjung Lesung adalah sebagai berikut :

- Batas Utara : Selat Sunda,

- Batas Selatan : Selat Sunda,

- Batas Timur : Selat Sunda,

- Batas Barat : Desa Tanjung Jaya

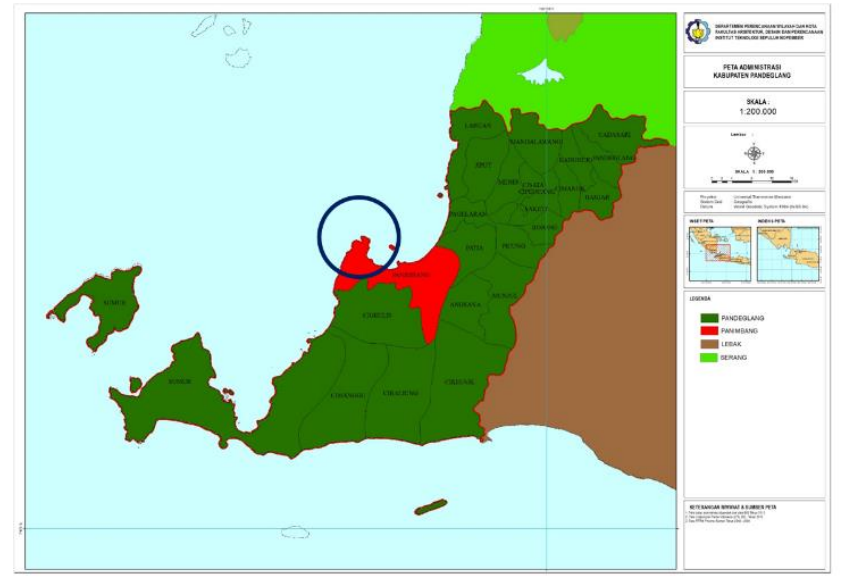

Gambar 1. Peta Lokasi KEK Tanjung Lesung

Pembentukan Kawasan Ekonomi Khusus Tanjung Lesung dalam rangka pembangunan perekonomian di Kawasan Tanjung Lesung dan untuk menunjang percepatan dan perluasan pembangunan ekonomi nasional memiliki luasan sebesar 1.500 ha. Jarak dari Jakarta menuju KEK Tanjung Lesung $160 \mathrm{Km}$ dengan waktu tempuh 3 - 4 Jam perjalanan dengan menggunakan kendaraan pribadi, dan berjarak $80 \mathrm{Km}$ dari ibukota Provinsi Banten. Namun jaringan jalan yang tersedia menuju ke KEK tanjung Lesung hanya terdiri dari 2 lajur dengan perkiraan lebar $6-8$ meter, serta hanya memiliki 1 alternatif rute jalan selepas dari Ibukota Kabupaten Pandeglang, untuk moda tranportasi yang dapat menjangkau KEK tanjung lesung hanya kendaraan pribadi baik kendaraan beroda 2 ataupun beroda 4 . Untuk fasilitas kesehatan rumah sakit terdekat ada di ibukota kabupaten Pandeglang dengan jarak sekitar $60 \mathrm{Km}$ dengan waktu tempuh 1,5 jam hingga 2 jam. Untuk puskesmas terdekat, ada puskesmas Panimbang yang berjarak $18 \mathrm{Km}$ dari KEK tanjung lesung dengan jarak tempuh $20-30$ menit. 
Infrastuktur merupakan roda penggerak pertumbuhan suatu wilayah. Ketidakcukupan infrastruktur merupakan salah satu kunci terjadinya hambatan bagi pertumbuhan ekonomi yang lebih cepat [2]. Simon Kuznet menyatakan bahwa ketersediaan infrastuktur sangat menentukan tingkat keefisienan dan keefektifan kegiatan ekonomi serta merupakan prasyarat agar berputarnya roda perekonomian berjalan dengan baik [3]. Infrastruktur sebagai prasarana jaringan dasar dari keberadaan suatu kota atau wilayah merupakan faktor penting di dalamkeberlangsungan dan pertumbuhan kota atau wilayah [4]. Apabila di dalam penyediaan dan pemeliharaan infrastruktur tidak dilakukan dengan baik, maka jaringan kota atau simpul kegiatan perkotaan didalam suatu wilayah menjadi terganggu, yang selanjutnya berdampak kepada degradasi sistem ekonomi dan sosial masyarakat [5].

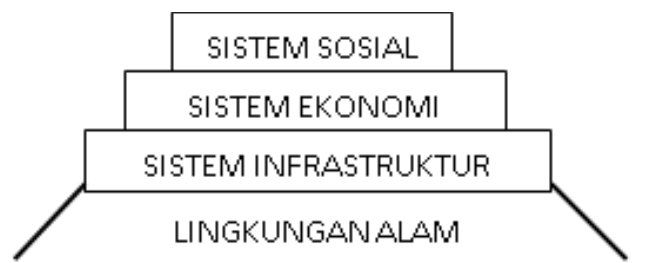

Gambar 2. Infrastruktur Sebagai Penopang/pendukung Sistem Ekonomi, Sosial-budaya, Kesehatan dan Kesejahteraan

Pengadaan dan pengelolaan infrastruktur merupakan salah satu dari dua modal utama pembangunan suatu daerah, oleh karenanya diperlukan suatu studi mengenai identifikasi infrastruktur untuk pengembangan kegiatan - kegiatan strategis suatu kawasan [6]. Oleh sebab itu, dalam melakukan pembangunan KEK pariwisata Tanjung Lesung, diperlukan prioritas pengembangan infrastruktur pendukung agar dapat mempercepat pembangunan KEK Tanjung Lesung.

\section{METODE PENELITIAN}

\section{A. Jenis dan Pendekatan Penelitian}

Jenis penelitian ini adalah penelitian deskriptif kualitatif dengan pendekatanyang digunakan rasionalistik [7]

\section{B. Variabel Penelitian}

Variabel penelitian yang digunakan untuk mengidentifikasi kebutuhan infrastruktur penunjang pembangunan KEK Tanjung Lesung adalah fasilitas penginapan dan hotel; restaurant dan tempat makan lainnya; fasilitas pelayanan kesehatan; fasilitas pelayanan keuangan; fasilitas pelayanan keamanan; fasilitas pelayanan perbelanjaan; penyediaan air bersih; jaringan listrik; sistem drainase; sistem pengelolaan limbah dan sanitasi; telekomunikasi; persampahan; kondisi jalan; moda transportasi; fasilitas pendukung transportasi. Adapun untuk variabel dalam menentukan prioritas infrastruktur yang dibutuhkan guna mempercepat pembangunan KEK Tanjung Lesung adalah hasil dari identifikasi dari kebutuhan infrastruktur penunang pembangunan KEK Tanjung Lesung.

\section{Mengidentifikasi Kebutuhan Infrastruktur Penunjang} Pembangunan KEK Tanjung Lesung

Analisis yang digunakan dalam mengidentifikasi kebutuhan infrasrtuktur penunjang pembangunan KEK Tanjung Lesung adalah Delphi Analysis. Analisis Delphi memiliki karakteristik sebagai suatu metode untuk menstrukturkan proses komunikasi kelompok agar proses tersebut efektif dalam memberikan kesempatan pada kelompok atau individu dalam memecahkan masalah yang kompleks [8].

Metode ini dilakukan dengan Kuisioner kepada responden terpilih sesuai dengan Lampiran untuk menilai variabel variabel penelitian berdasarkan keahlian dan pemahaman mengenai kawasan penelitian. Responden diharapkan memberikan penilaian mengenai variabel - variabel penelitian yang sudah didapatkan kemudian hasil dari penilaian ini adalah fiksasi mengenai variabel - variabel apa saja yang relevan untuk dilanjutkan dalam menentukan prioritas infrastruktuktur yang dibutuhkan KEK Tanjung Lesung.

Dalam mencari konsensus dilakukan iterasi kepada antar responden, jika terlah tercapai konsensus maka hasil itu yang akan menjadi hasil identifikasi kebutuhan infrasrtuktur penunjang pembangunan KEK Tanjung Lesung, bila belum mencapai konsensus maka akan dilakukan iterasi hingga dihasilkan variabel - variabel yang konsensus antar responden

\section{Penentuan Prioritas Infrastruktur Yang Dibutuhkan Guna Mempercepat Pembangunan KEK Tanjung Lesung.}

Analisayang digunakan untuk menentukan prioritas infrastruktur yang dibutuhkan guna mempercepat pembangunan KEK Tanjung Lesung adalah Analytical Hierarchy Process (AHP). AHP adalah analisis yang digunakanuntuk menyederhanakan suatu permasalahanyang kompleks yang tidak tersruktur, strategis, dan dinamik menjadi bagian-bagian serta menata dalam suatu hierarki [9]. AHP juga memungkinkan pengguna untuk memberikan nilai bobot relatif dari suatu kriteria majemuk secara intuitif. Berikut tahapan dalam melakukan AHP :

\section{1) Mengidentifikasi Permasalahan}

Identifikasi permasalahan berkaitan dengan penetapan tujuan dari penelitian ini dilakukan.

\section{2) Sintesa hierarki}

Faktor yang akan digunakan sebagai input dari analisi ini adalah hasil dari studi literatur yang telah dilakukan serta dikomparasikan dengan hasil dari sasaran 1.

\section{3) Penyebaran kuisioner}

Kuisioner AHP berisi perbandingan tingkat tiap variabel dari identifikasi faktor - faktor yang mempengaruhi pengembangan KEK Tanjung Lesung.

\section{4) Pengolahan matrik berpasangan}

Nilai perbandingan hasil dari kuisioner akan diolah kedalam pairwise individual dengan menggunakan bantuan software expert choice, dimana dimasukan nilai bobot dari hasil kuisioner pada masing - masing preferensi individu responden. 5) Perhitungan bobot faktor dan uji konsistensi

Perhitungan bobot dilakukan dengan menggunakan software expert choice sehingga dari hasil penyebaran kuisioner dan matriks berpasangan yang dipilih berdasarkan pendapat dan pengalaman masing - masing responden, maka nilai bobot diketahui dari masing - masing nilai bobot tiap variabelnya. Sehingga dapat diketahui prioritas (prioritas derived) faktor dengan nilai inkosistensinya.

6) Penentuan faktor - faktor

Penentuan faktor - faktor yang terpilih dilakukan dengan interpretasi dari nilai bobot tiap variabel dan nilai inkosistensinya $<0,1$. 


\section{HASIL DAN DISKUSI}

\section{A. Mengidentifikasi Kebutuhan Infrastruktur Penunjang} Pembangunan KEK Tanjung Lesung

Berdasarkan kajian teori dan literatur yang telah dilakukan, didapatkan hasil dan variabel terkait mengidentifikasi kebutuhan infrastruktur penunjang pembangunan KEK Tanjung Lesung sebagai berikut :

Tabel 1

Variabel dan Definis Operasional

\begin{tabular}{|c|c|c|}
\hline Indikator & Variabel & Definisi Operasional \\
\hline \multirow{8}{*}{$\begin{array}{l}\text { Akomodasi } \\
\text { Wisata, } \\
\text { Fasilitas dan } \\
\text { Pelayanan } \\
\text { Wisata }\end{array}$} & Fasilitas & \multirow{2}{*}{$\begin{array}{l}\text { Ketersedian fasilitas penginapan } \\
\text { yang tersedia }\end{array}$} \\
\hline & $\begin{array}{l}\text { Penginapan } \\
\text { Hotel }\end{array}$ & \\
\hline & $\begin{array}{lr}\text { Restoran } & \text { dan } \\
\text { tempat } & \text { makan } \\
\text { lainnya } & \\
\end{array}$ & $\begin{array}{l}\text { Ketersedian restauran dan tempat } \\
\text { makan yang telah tersedia }\end{array}$ \\
\hline & $\begin{array}{l}\text { Fasilitas Pelayanan } \\
\text { Kesehatan }\end{array}$ & $\begin{array}{l}\text { Ketersediaan fasilitas pelayanan } \\
\text { kesehatan }\end{array}$ \\
\hline & $\begin{array}{l}\text { Fasilitas Pelayanan } \\
\text { Keuangan }\end{array}$ & $\begin{array}{l}\text { Ketersediaan fasilitas pelayanan } \\
\text { keuangan }\end{array}$ \\
\hline & $\begin{array}{l}\text { Fasilitas Pelayanan } \\
\text { Keamanan }\end{array}$ & $\begin{array}{l}\text { Ketersediaan fasilitas pelayanan } \\
\text { keamanan }\end{array}$ \\
\hline & Fasilitas Pelayanan & Ketersediaan fasilitas pelayanan \\
\hline & $\begin{array}{l}\text { Perbelanjaan } \\
\text { Souvenir Shop }\end{array}$ & perbelanjaan \\
\hline \multirow[t]{6}{*}{ Utilitas } & $\begin{array}{l}\text { Penyediaan Air } \\
\text { Bersih }\end{array}$ & $\begin{array}{l}\text { Ketersediaan dan persebaran air } \\
\text { bersih }\end{array}$ \\
\hline & $\begin{array}{l}\text { Penyediaan } \\
\text { Jaringan Listrik }\end{array}$ & $\begin{array}{l}\text { Ketersedian dan keterjangkauan } \\
\text { jaringan listrik }\end{array}$ \\
\hline & $\begin{array}{l}\text { Penyediaan Sistem } \\
\text { Drainase }\end{array}$ & $\begin{array}{l}\text { Ketersediaan jaringan drainase } \\
\text { dan kualitasnya }\end{array}$ \\
\hline & $\begin{array}{l}\text { Sistem Pengelolaan } \\
\text { Limbah dan } \\
\text { Sanitasi }\end{array}$ & $\begin{array}{l}\text { Ketersediaan IPAL dan Sanitasi } \\
\text { serta sistem yang tersedia }\end{array}$ \\
\hline & Telekomunikasi & $\begin{array}{l}\text { Ketersediaan dan kemerataan } \\
\text { fasilitas telekomunikasi }\end{array}$ \\
\hline & Persampahan & $\begin{array}{l}\text { Ketersediaan dan persedabaran } \\
\text { persampahan }\end{array}$ \\
\hline \multirow[t]{3}{*}{$\begin{array}{l}\text { Aksesbilitas } \\
\text { dan } \\
\text { Transportasi }\end{array}$} & Kondisi Jalan & $\begin{array}{l}\text { Kualitas dari jaringan jalan yang } \\
\text { sudah ada dan Rencana } \\
\text { keterhubungan di dalam Kawasan } \\
\text { serta jaringan jalan penghubung } \\
\text { dari dan ke kawasan Tanjung } \\
\text { Lesung }\end{array}$ \\
\hline & Moda Transportasi & $\begin{array}{l}\text { Ketersediaan angkutan } \\
\text { transportasi darat, laut dan udara } \\
\text { yang ada di dalam kawasan serta } \\
\text { dari dan ke dalam kawasan }\end{array}$ \\
\hline & $\begin{array}{l}\text { Fasilitas Pendukung } \\
\text { Transportasi }\end{array}$ & $\begin{array}{l}\text { Ketersediaan fasilitas pendukung } \\
\text { transportasi yang ada dan akan } \\
\text { dibangun, seperti terminal, } \\
\text { Bandara, Pelabuhan. }\end{array}$ \\
\hline
\end{tabular}

Pendefinisian nilai yang diberikan oleh responden adalah sebagai berikut :

$\mathrm{S}=$ Setuju

TS = Tidak Setuju

Adapun pemilihan Responden berdasarkan hasil analisa stakeholder (Lampiran). Analisa Delphi dilakukan dengan menyebar kuisioner pada responden terpilih. Kuisioner ditanyakan beberapa kali kepada tiap responden hingga tercapai konsensus dari semua responden terpilih dari masing - masing variabel yang telah didapatkan. Adapun proses analisis Delphi yang telah dilakukan dalam menenukan variabel - variabel kebutuhan infrasrtuktur penunjang pembangunan KEK tanjung lesung adalah sebagai berikut :

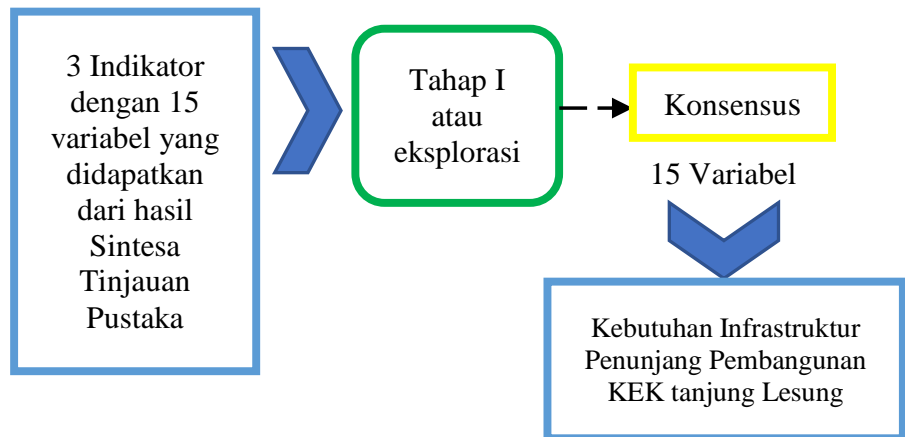

Gambar 3. Alur Analisis Delphi Yang Telah Dilakukan.

Adapun hasil dari analisis ini didapatkan keseluruhan infrastruktur yang dibutuhkan KEK Tanjung Lesung ada 15 sesuai dengan hasil tinjauan literatur yang telah dilakukan.

\section{B. Penentuan Prioritas Infrastruktur Yang Dibutuhkan Guna Mempercepat Pembangunan KEK Tanjung Lesung}

Terdapat tiga faktor yang masuk dalam tahap analisis ini dengan keseluruhan variabel berjumlah lima belas untuk mencari prioritas infrastruktur yang dibutuhkan guna mempercepat pembangunan KEK Tanjung Lesung. Adapun stakeholder yang berpartisipasi pada analisis ini terdapat enam stakeholder. Proses penentuan prioritas infrastruktur menggunakan analisis AHP (Analytical Hoerarki Process). Tahapan pencarian prioritas ini dilakukan pembobotan terhadap tiap faktor yang ada dan tiap variabelnya. Sehingga dapat diketahui bobot dari tiap faktor yang ada lalu tiap variabel yang ada. Selanjutnya dari hasil pengisian kuisioner tersebut diolah menggunakan aplikasi expert choice v11. Aplikasi ini akan membandingkan tiap faktor yang ada dan tiap variabel yang ada sehingga akan keluar bobotnya masing - masing.

1) Pembobotan Antar Faktor

Hasil analisis didapatkan bobot akhir untuk tiap indikator sebagai berikut :
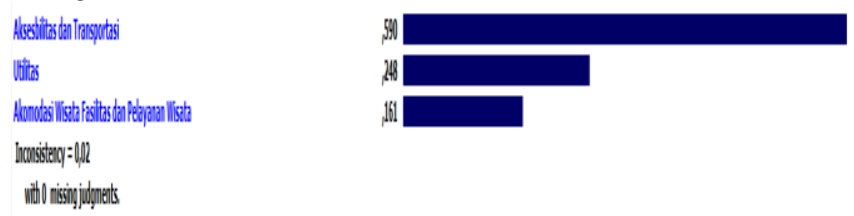

Gambar 4. Bobot Prioritas Faktor

Dari Hasil diatas dapat diketahui bahwa nilai prioritas terbesar adalah faktor Aksesbilitas dan Transportasi dengan nilai 0,590 ; Utilitas 0,248; Akomodasi wisata Fasilitas dan Pelayanan wisata 0,161 ; dengan nilai inkosistensi 0,02 maka keempat faktor tersebut dianggap Valid karena $<0,1$. Dari nilai ini dapat diketahui Faktor dengan Prioritas tertinggi adalah faktor Aksesbilitas dan Transportasi dan untuk Prioritas terendah adalah faktor Pengorganisasian Pengembangan Infrastruktur.

2) Pembobotan Antar Variabel Pada Faktor Akomodasi Wisata Fasilitas dan Pelayanan Wisata.

Hasil analisis didapatkan bobot prioritas akhir untuk tiap variabel pada faktor Akomodasi Wisata Fasilitas dan Pelayanan Wisata adalah sebagai berikut : 


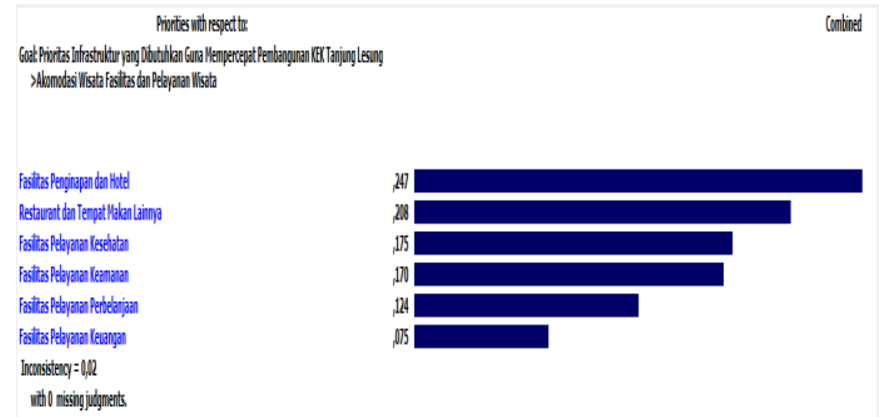

Gambar 5. Bobot Prioritas Variabel Pada Faktor Akomodasi Wisata Fasilitas dan Pelayanan Wisata.

Dari hasil diatas dapat diketahui bahwa variabel Fasilitas Penginapan dan Hotel memiliki nilai bobot tertinggi dengan nilai 0,247 ; Lalu Restaurant 0,208 ; Fasilitas Pelayanan Kesehatan 0,175; Fasilitas Pelayanan Keamanan 0,170; Fasilitas Pelayanan Perbelanjaan 0,124; dan yang terendah adalah Fasilitas Pelayanan Keuangan. Hasil ini valid karena nilai inconsistency nya bernilai 0,02 .

3) Pembobotan Antar Variabel Pada Faktor Utilitas

Hasil analisis didapatkan bobot prioritas akhir untuk tiap variabel pada faktor Utilitas adalah sebagai berikut : Prontios ribl respectlo:

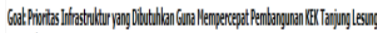

Notitas

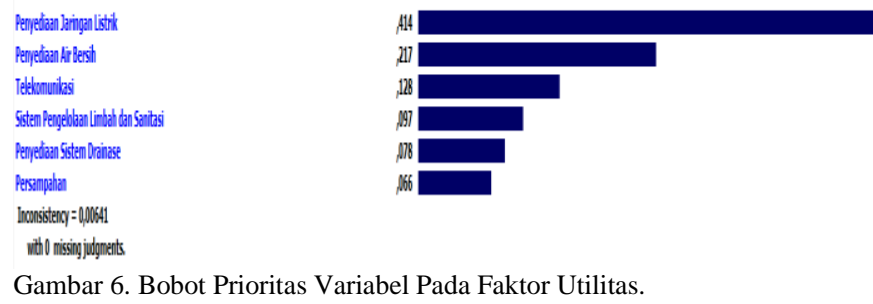

Dari hasil diatas dapat diketahui nilai prioritas variabel yang ada pada faktor Utilitas terbesar dimiliki oleh variabel Penyediaan Jaringan Listik dengan nilai 0,414 ; lalu Penyediaan Air bersih 0,217; Telekomunikasi 0,128; Sistem Pengelolaan Limbah dan Sanitasi 0,097 ; Penyediaan Sistem drainase 0,078; dan Persampahan memiliki nilai prioritas terendah dengan nilai 0,066. Hasil ini valid dikarenakan nilai inconsistency yang bernilai <0,1 yaitu 0,00641.

4) Pembobotan Antar Variabel Pada Faktor Aksesbilitas dan Transportasi

Hasil analisis didapatkan bobot prioritas akhir untuk tiap variabel pada faktor Aksesbilitas dan Transportasi adalah sebagai berikut :
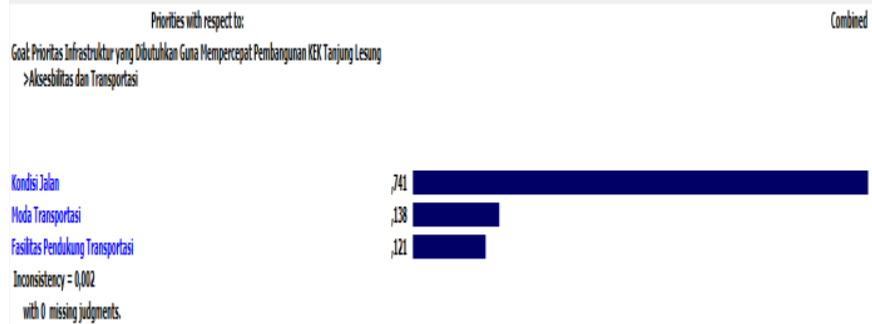

iith rissigingugnets

Gambar 7. Bobot Prioritas Variabel Pada Faktor Aksesbilitas dan Transportasi.

Dari hasil diatas diketahui bahwa pada faktor Aksesbilitas dan Transportasi variabel yang memiliki nilai prioritas tertinggi adalah Kondisi Jalan dengan nilai 0,741; lalu disusul Moda transportasi 0,138; dan terendah Fasilitas pendukung transportasi 0,121. Hasil ini dikatakan valid karena nilai Inconsistencynya $0,002<0,1$.

\section{5) Pembobotan Antar Variabel Keseluruhan}

Hasil dari analisis AHP untuk keseluruhan variabel yang digunakan dalam analisis ini adalah sebagai berikut :

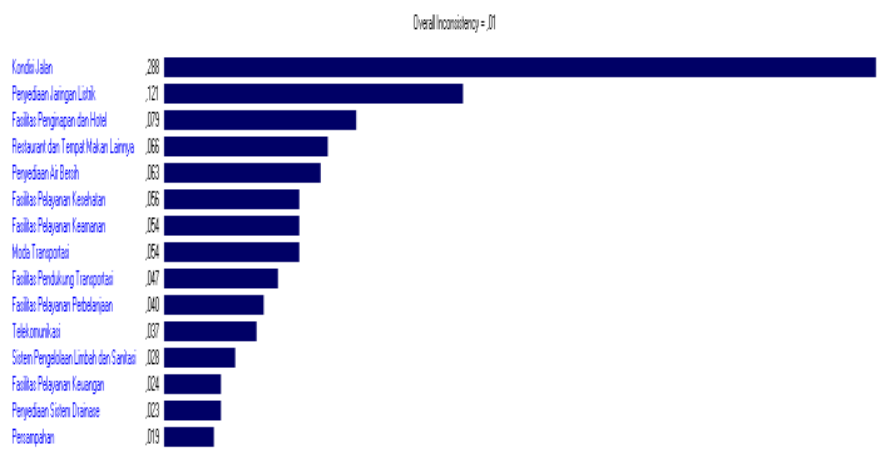

Gambar 8. Bobot Prioritas Variabel Keseluruhan.

Dari hasil diatas dapat diketahui prioritas infrastruktur yang diperlukan di KEK Tanjung Lesung yaitu :

1. Kondisi Jalan dengan nilai 0,288

2. Penyediaan Jaringan Listrik dengan nilai 0,121

3. Fasilitas Penginapan dan Hotel dengan nilai 0,079

4. Restaurant dan Tempat Makan dengan nilai 0,066

5. Penyediaan Air Bersih dengan nilai 0,063

6. Fasilitas Pelayanan Kesehatan dengan nilai 0,056

7. Fasilitas Pelayanan Keamanan dengan nilai 0,054

8. Moda Transportasi dengan nilai 0,054

9. Fasilitas Pendukung Transportasi dengan nilai 0,047

10. Fasilitas Pelayanan Perbelanjaan dengan nilai 0,040

11. Telekomunikasi dengan nilai 0,037

12. Sistem Pengelolaan Limbah dan Sanitasi dengan nilai 0,028

13. Fasilitas Pelayanan Keuangan dengan nilai 0,024

14. Penyediaan Drainase dengan nilai 0,023

15. Persampahan dengan nilai 0,019

\section{KESIMPULAN}

Pada penelitian ini bertujuan untuk menentukan prioritas infrastruktur penunjang yang dibutuhkan guna mempercepat pembangunan KEK Tanjung Lesung. Berdasarkan hasil penelitian ini terdapat lima belas infrastruktur penunjang yang diperlukan oleh KEK Tanjung Lesung yaitu fasilitas penginapan dan hotel; restaurant dan tempat makan lainnya; fasilitas pelayanan kesehatan; fasilitas pelayanan keuangan; fasilitas pelayanan keamanan; fasilitas pelayanan perbelanjaan; penyediaan air bersih; jaringan listrik; sistem drainase; sistem pengelolaan limbah dan sanitasi; telekomunikasi; persampahan; kondisi jalan; moda transportasi; fasilitas pendukung transportasi dengan 5 infrastrutktur yang menjadi prioritas yaitu (1) Kondisi jalan (2) penyediaan jaringan listrik (3) fasilitas penginapan dan hotel (4) restaurant dan tempat makan lainnya (5) Penyediaan air bersih. 
JURNAL PENATAAN RUANG Vol. 13, No. 2, (2018) ISSN: 2716-179X (1907-4972 Print)

\section{LAMPIRAN}

Tabel 2.

Keterangan Analisis Stakeholder

\begin{tabular}{ll}
\hline \hline Importance (kepentingan) & Influence (Pengaruh) Stakeholder \\
Stakeholder terhadap Pengembangan & terhadap pengembangan KEK \\
KEK Tanjung Lesung & Tanjung Lesung \\
\hline $1=$ little/ no importance & $1=$ little / no inluence \\
$2=$ some importance & $2=$ some influence \\
$3=$ moderate importance & $3=$ moderate influence \\
$4=$ very importance & $4=$ significant influence \\
$5=$ critical player & $5=$ very influential \\
\hline \hline
\end{tabular}

Tabel 3.

Analisis Stakeholder

Tingkat Pengaruh

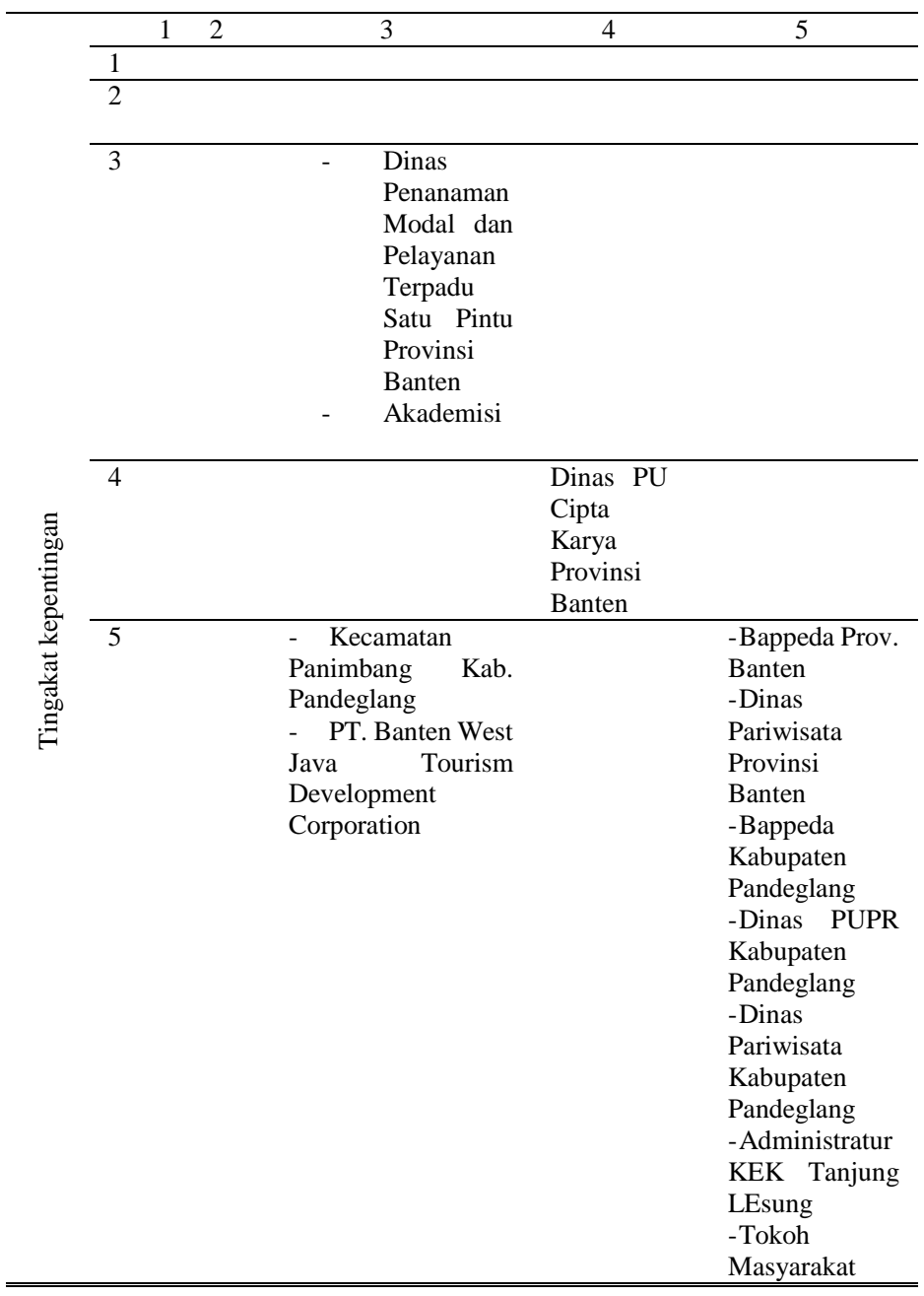

Hasil analisa stakeholder menunjukan bahwa responden yang dapat dijadikan narasumber pada penelitian ini adalah BAPPEDA Provinsi Banten, Dinas Pariwisata Provinsi Banten, Dinas Pekerjaan Umum dan Cipta Karya Provinsi Banten, BAPPEDA Kabupaten Pandeglang, Dinas Pariwisata Kabupaten Pandeglang, Dinas Pekerjaan Umum dan Cipta Karya Kabupaten Pandeglang, PT Banten West Java Tourism, Administrator KEK Tanjung Lesung dan Tokoh Masyarakat

\section{DAFTAR PUSTAKA}

[1] Undang-Undang tentang Kawasan Ekonomi Khusus, Undang-Undang No. 39 tahun 2009

[2] Kodoatie, Robert. 2005. Pengantar Manajemen Infrastruktur Pustaka Pelajar: Yogyakarta

[3] Maqin, A. (2011). Pengaruh Kondisi Infrastruktur terhadap Pertumbuhan Ekonomi di Jawa Barat, Bandung.

[4] Grigg, N. 1988, Infrastructure Engineering and Management, John Wiley \& Sons.

[5] Kodoatie, Robert. 2005. Pengantar Manajemen Infrastruktur Pustaka Pelajar: Yogyakarta

[6] Grigg, N. Dan Fontane, D. G. 2000, Infrastructure System Management \& Optimazation Internasional Civil Engineering Departement Diponegoro University

[7] Sugiyono, Prof, Dr. 2006. Metode Penelitian Pendidikan (Pendekatan Kuantitatif, Kualitatif, $R \& D$ ). Bandung : Alfabeta

[8] Muchlis, Surya. (2017). Arahan Pengembangan Agrowisata Berdasarkan Potensi Sumber daya Lokal di Kecamatan Sukapura Kabupaten Probolinggo. Surabaya : ITS

[9] Noor, Juliansyah. (2001). Metodologi Penelitian Skripsi, Tesis, Disertasi, dan Karya Ilmiah. Jakarta : Kencana 